\title{
FTIR Study of Copper Agglomeration during Atomic Layer Deposition of Copper
}

\section{Citation}

Dai, Min, Jinhee Kwon, Yves J. Chabal, Mathew D. Halls, and Roy Gerald Gordon. 2009. FTIR study of copper agglomeration during atomic layer deposition of copper. In CCMOS gate-stack scaling -- Materials, interfaces, and reliability implications, Vol. 1155, MRS Proceedings 2009: April 13-16, 2009, San Francisco, CA, ed. Alexander A. Demkov, et al., 1155-C11-06. Warrendale, PA: Materials Research Society.

\section{Published Version}

doi:10.1557/PROC-1155-C11-06

\section{Permanent link}

http://nrs.harvard.edu/urn-3:HUL.InstRepos:8886763

\section{Terms of Use}

This article was downloaded from Harvard University's DASH repository, and is made available under the terms and conditions applicable to Open Access Policy Articles, as set forth at http:// nrs.harvard.edu/urn-3:HUL.InstRepos:dash.current.terms-of-use\#OAP

\section{Share Your Story}

The Harvard community has made this article openly available.

Please share how this access benefits you. Submit a story.

Accessibility 


\title{
FTIR study of copper agglomeration during atomic layer deposition of copper
}

Min Dai, ${ }^{1}$ Jinhee Kwon, ${ }^{2}$ Yves J. Chabal, ${ }^{2}$ Mathew D. Halls, ${ }^{3}$ and Roy G. Gordon ${ }^{4}$

${ }^{1}$ Laboratory for Surface Modification, Rutgers University, 136 Frelinghuysen Road, Piscataway, NJ 08854, U. S. A.

${ }^{2}$ Department of Materials Science and Engineering, The University of Texas at Dallas, Richardson, TX 75080, U.S.A.

${ }^{3}$ Materials Science Division, Accelrys Inc., San Diego, CA 92121, U.S.A.

${ }^{4}$ Department of Chemistry and Chemical Biology, Harvard University

Cambridge, MA 02138, U.S.A.

\begin{abstract}
The growth of of metallic copper by atomic layer deposition (ALD) using copper(I) di-secbutylacetamidinate $\left(\left[\mathrm{Cu}\left({ }^{\mathrm{s}} \mathrm{Bu} \text {-amd }\right)\right]_{2}\right)$ and molecular hydrogen $\left(\mathrm{H}_{2}\right)$ on $\mathrm{SiO}_{2} / \mathrm{Si}$ surfaces has been studied. The mechanisms for the initial surface reaction and chemical bonding evolutions with each ALD cycle are inferred from in situ Fourier transform infrared spectroscopy (FTIR) data. Spectroscopic evidence for $\mathrm{Cu}$ agglomeration on $\mathrm{SiO}_{2}$ is presented involving the intensity variations of the $\mathrm{SiO}_{2} \mathrm{LO} / \mathrm{TO}$ phonon modes after chemical reaction with the $\mathrm{Cu}$ precursor and after the $\mathrm{H}_{2}$ precursor cycle. These intensity variations are observed over the first 20 ALD cycles at $185^{\circ} \mathrm{C}$.
\end{abstract}

\section{INTRODUCTION}

Atomic layer deposition (ALD) has recently received great interest with the need for new materials and thin-film deposition techniques for device scaling in integrated circuits (IC). The self-limiting growth mechanism of ALD is ideal for producing very thin, conformal films even on surfaces with high aspect ratios with control of the thickness and composition at the atomic level. As the industry heads toward the $22 \mathrm{~nm}$ node, the interest in metal ALD is growing, especially for copper interconnects. $\mathrm{Cu}$ is replacing aluminum as an interconnect material in ICs due to its lower resistivity $\left(1.72 \times 10^{-6} \Omega \cdot \mathrm{cm}\right.$ vs. $\left.2.82 \times 10^{-6} \Omega \cdot \mathrm{cm}\right)$ and higher melting point $(1083$ ${ }^{\circ} \mathrm{C}$ vs. $659^{\circ} \mathrm{C}$ ). ${ }^{1}$ For this application, a highly conformal and continuous copper seed layer is required before subsequent electrochemical deposition of copper film with high growth rate. ${ }^{2}$

ALD of non-noble metals, however, has had limited success ${ }^{3,4}$. One of the reasons for these difficulties is related to a lack of suitable precursors which satisfy stringent requirements for ALD. ${ }^{5}$ In addition, the lack of understanding of growth mechanisms of metal ALD hinders the development of suitable precursors.

ALD of $\mathrm{Cu}$ has been considered previously. Several copper (I) and copper (II) precursors were commonly used in the past, such as $\mathrm{CuCl}^{4,6}, \mathrm{Cu}(\mathrm{II})-2,2,6,6$-tetramethyl-3,5-heptandionate $\left[\mathrm{Cu}(\text { thd })_{2}\right]^{7,8}, \mathrm{Cu}(\mathrm{II})-1,1,1,5,5,5$-hexafluoro-2,4 -pentanedionate $\left[\mathrm{Cu}(\mathrm{hfac})_{2}\right]^{9,10}$, and $\mathrm{Cu}(\mathrm{II})$ acetylacetonate $\left[\mathrm{Cu}(\mathrm{acac})_{2}\right]^{11,12}$, but all suffered from undesirable properties as ALD 
precursors. ${ }^{13}$ For example, $\mathrm{CuCl}$ has very low vapor pressure, and the $\mathrm{Cu}$ film deposited by $\mathrm{Cu}(\mathrm{hfac})_{2}$ contains fluorine which reduces the $\mathrm{Cu}$ adhesion on the substrate. They all have very low reactivity with low growth rate, so that either high temperature $\left(>200^{\circ} \mathrm{C}\right)$, which is not well suited for smooth $\mathrm{Cu}$ growth due to $\mathrm{Cu}$ agglomeration and diffusion ${ }^{13-15}$, or plasma is needed to enhance the reactivity.

Recently, Gordon et al. ${ }^{16}$ reported ALD growth of metallic copper with high conformality and high conductivity using an amidinate precursor (copper (I) di-sec-butylacetamidinate, $\left.\left[\mathrm{Cu}\left({ }^{\mathrm{s}} \mathrm{Bu}-\mathrm{amd}\right)\right]_{2}\right)$ and molecular hydrogen at relatively low temperature $\left(\sim 185^{\circ} \mathrm{C}\right)$. One of the advantages of this precursor is its high reactivity with molecular hydrogen at reasonable temperatures. In order to understand the ALD Cu growth mechanisms with this amidinate precursor, we used in-situ Fourier transform infrared spectroscopy (FTIR) to investigate the chemical bonding evolution after each ALD cycle.

\section{EXPERIMENT}

Double side polished, float-zone grown, and lightly doped $(\sim 10 \Omega \cdot \mathrm{cm}) \operatorname{Si}(100)$ with thin thermal oxide (6-10 nm thick $\mathrm{SiO}_{2}$ ) is used. The sample is first rinsed by acetone, methanol, and deionized water (DI water, $18.2 \mathrm{M} \Omega \cdot \mathrm{cm}$ ), then standard RCA ${ }^{17,18}$ cleaning is performed followed by thorough rinsing with deionized water and blow-drying with $\mathrm{N}_{2}$. Then the sample is immediately loaded in the ultra pure $\mathrm{N}_{2}$ (oxygen impurity $<10^{-3} \mathrm{ppm}$ ) purged ALD chamber.

All experiments are done in a home-made ALD system integrated with a Thermo Nicolet 670 interferometer and a MCT/B detector for in-situ FTIR measurements. ${ }^{19}$ A single-pass transmission geometry is used with an incidence angle close to the Brewster angle to maximize transmission, minimize interference, and increase sensitivity to absorptions below $\sim 1500 \mathrm{~cm}^{-1}$. Distinction of perpendicular from parallel modes to the surface is made by additional normal incidence measurements. Mid-infrared range of $400-4000 \mathrm{~cm}^{-1}$ is scanned with the resolution of $4 \mathrm{~cm}^{-1}$.

$\left[\mathrm{Cu}\left({ }^{\mathrm{s}} \mathrm{Bu} \text {-amd }\right)\right]_{2}$ is kept at $95-100^{\circ} \mathrm{C}$, and purified $\mathrm{N}_{2}$ is used as the carrier gas to deliver the copper precursor. $\mathrm{Cu}$ film is deposited by introducing $\left[\mathrm{Cu}\left({ }^{5} \mathrm{Bu} \text {-amd) }\right]_{2}\right.$ (exposure $\sim 10^{7} \mathrm{~L}$ ) and $\mathrm{H}_{2}$ (exposure $\sim 10^{11} \mathrm{~L}$ ) (ultra high purity, 99.999\%, purified by Aeronex Gate Keeper gas purifiers) alternatively into the ALD chamber. During deposition, the substrate temperature is kept at $185^{\circ} \mathrm{C}$ for optimum $\mathrm{Cu}$ deposition. After each precursor dosing, the ALD chamber is $\mathrm{N}_{2}$-purged thoroughly with pumping.

\section{RESULTS AND DISCUSSION}

Figure 1 shows differential IR absorbance spectra of the first cycle of $\mathrm{Cu} A L D$ on $\mathrm{SiO}_{2}$ at $185^{\circ} \mathrm{C}$, where the maximum $\mathrm{Cu}$ growth rate is observed. ${ }^{13}$ Upon the first half cycle when the $\mathrm{Cu}$ precursor $\left[\mathrm{Cu}\left({ }^{\mathrm{s}} \mathrm{Bu} \text {-amd) }\right]_{2}\right.$ (black) is introduced, the intensity of the transverse and longitudinal optical modes (TO/LO) of $\mathrm{SiO}_{2}$ at $1075 / 1247 \mathrm{~cm}^{-1}$ decreases. Their intensity loss indicates that the $\mathrm{SiO}_{2}$ matrix is chemically disrupted due to the reaction of the $\mathrm{Cu}$ precursor with surface $\mathrm{OH}$ groups. The absorption band at $1010 \mathrm{~cm}^{-1}$ corresponds to the formation of Si-O-Cu bonds due to the adsorbed $\mathrm{Cu}$ precursor on $\mathrm{SiO}_{2}$. The reaction scheme is shown as the inset in the right. Upon the $\mathrm{H}_{2}$ exposure (red), there is a partial recovery of $\mathrm{SiO}_{2}$ phonon modes $\left(1075 / 1247 \mathrm{~cm}^{-1}\right)$. The recovery of these modes suggests that after the $\mathrm{H}_{2}$ dosing, the $\mathrm{Cu}$ precursor on the surface is reduced to pure copper atoms which then migrate and self-agglomerate to form copper particles 
$13,21,22$. As they agglomerate, the chemical bonds established during the first half cycle between $\mathrm{Cu}$ and the underlying $\mathrm{SiO}_{2}$ matrix are broken and rehydroxylated, partially restoring the $\mathrm{SiO}_{2}$ phonon modes and hydroxyl sites on the surface.

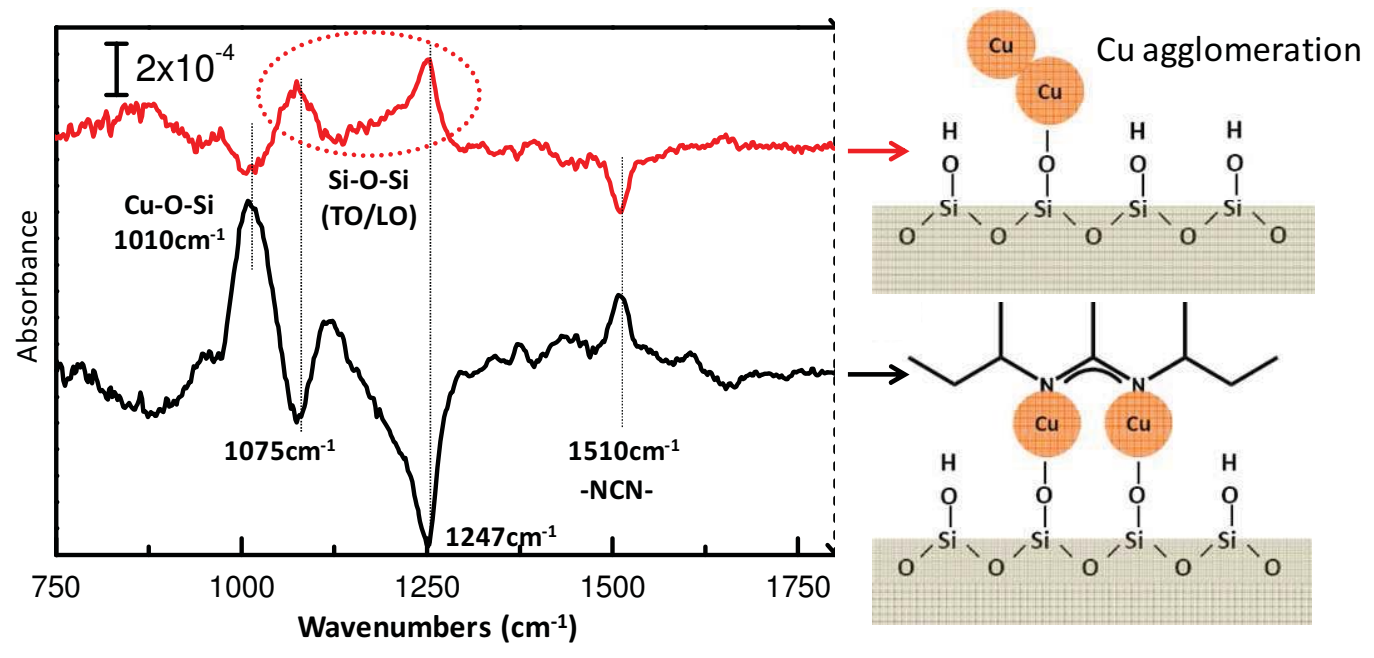

Figure 1. Differential IR absorbance spectra of the first cycle of $\mathrm{Cu} \mathrm{ALD}$ on $\mathrm{SiO}_{2}$ measured after the $\mathrm{Cu}$ precursor (black) and $\mathrm{H}_{2}$ (red) dosing. Each spectrum is referenced to the spectrum of the previous treatment and the bottom is referenced to initial oxide surface. The incident angle of IR beam is $74^{\circ}$. The inset in the right shows a schematic of surface reactions corresponding to observations in each spectrum.

In addition, the removal of the ligands by $\mathrm{H}_{2}$ reduction opens more reaction sites which were initially blocked by the intact ligands. In addition to the repetitive change of $\mathrm{SiO}_{2}$ phonon modes, the surface Si-O-Cu bonds at $1010 \mathrm{~cm}^{-1}$ follows the similar pattern of gain and recovery after $\mathrm{Cu}$ precursor and $\mathrm{H}_{2}$, respectively. This process is again schematically illustrated in the inset of Figure 1. The repetitive loss and gain of $\mathrm{SiO}_{2}$ modes are observed for the $20^{\text {th }}$ cycle, implying that the surface is not saturated and $\mathrm{Cu}$ atoms still agglomerate after 20 ALD cycles. This observation is consistent with the high percolation thickness for $\mathrm{Cu}$ on glass reported previously. ${ }^{13}$

In Figure 1, the mode at $1510 \mathrm{~cm}^{-1}$ is assigned to $v(\mathrm{~N}-\mathrm{C}-\mathrm{N})$ of the intact ligand attached to $\mathrm{Cu}$ atoms on the surface. Along with $\mathrm{CH}_{\mathrm{x}}$ stretching modes at 2800-3000 $\mathrm{cm}^{-1}$ (not shown), their intensity increases after each copper precursor and decreases after each $\mathrm{H}_{2}$, confirming the ALD process through ligand exchange.

$\mathrm{Cu}$ agglomeration (i.e. formation of $\mathrm{Cu}$ structures with substantially thicker diameter than the average $\mathrm{Cu}$ thickness) is also observed in the shape of Rutherford backscattering spectroscopy (RBS) of $\mathrm{Cu}$ in Figure 2. The areal density of $\mathrm{Cu}$ atoms is measured by ex situ RBS with $2 \mathrm{MeV} \mathrm{He}^{+}$ions. The detector is placed at $160^{\circ}$ backscattering angle. 


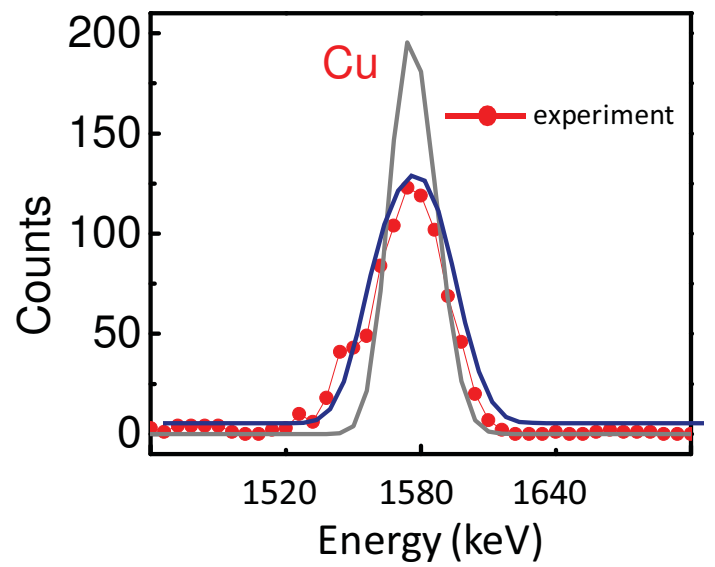

Figure 2. RBS spectrum (red dots) after 10 ALD cycles and simulations assuming uniform $\mathrm{Cu}$ coverage (gray) and non-uniform $\mathrm{Cu}$ coverage (blue). The detector is placed at a grazing angle of $160^{\circ}$ backscattering angle.

The FWHM of the simulation assuming uniform coverage of $\mathrm{Cu}$ atoms on the surface (gray) is narrower than that of the experimental RBS data (red dots). The blue line shows the simulated result after taking into account agglomerated $\mathrm{Cu}$ atoms of an island structure on the surface. The simulation of non-uniform $\mathrm{Cu}$ coverage is reasonably well fitted to the RBS data, confirming the agglomerated $\mathrm{Cu}$ on $\mathrm{SiO}_{2}$.

\section{CONCLUSIONS}

The surface reaction and the growth mechanism of $\mathrm{Cu}$ ALD with a liquid amidinate $\mathrm{Cu}$ precursor $\left([\mathrm{Cu}(\mathrm{sBu}-\mathrm{amd})]_{2}\right)$ and molecular hydrogen on oxidized $\mathrm{Si}$ surfaces $\left(6-10 \mathrm{~nm}\right.$ thick $\left.\mathrm{SiO}_{2}\right)$ have been investigated by using in situ FTIR spectroscopy and ex situ RBS. The agglomeration of $\mathrm{Cu}$ atoms on $\mathrm{SiO}_{2}$ was shown to have a significant effect on the evolution of $\mathrm{SiO}_{2}$ phonon modes. The hydrogen reduction of the surface ligand is observed through the modes attributed to $\mathrm{CH}_{\mathrm{x}}$ and -NCN- bonds, confirming ALD process through ligand exchange. The $\mathrm{Cu}$ agglomeration on the oxide is also confirmed by a broader RBS spectrum of $\mathrm{Cu}$.

\section{ACKNOWLEDGMENTS}

This work was supported by the National Science Foundation (CHE-0415652).

\section{REFERENCES}

1. The International Technology Roadmap for Semiconductors, Semiconductor Industry Association. http://pulic.itrs.net. 2005.

2. Jae Jeong, K.; Soo-Kil, K.; Chang Hwa, L.; Yong Shik, K., Investigation of various copper seed layers for copper electrodeposition applicable to ultralarge-scale integration interconnection. Journal of Vacuum Science \& Technology B 2003, 21, (1), 33-38. 
3. Lim, B. S.; Rahtu, A.; Gordon, R. G., Atomic layer deposition of transition metals. Nat Mater 2003, 2, (11), 749-754.

4. Marika, J.; Mikko, R.; Markku, L., Deposition of copper films by an alternate supply of $\mathrm{CuCl}$ and $\mathrm{Zn}$. Journal of Vacuum Science \& Technology A 1997, 15, (4), 2330-2333.

5. Musgrave, C.; Gordon, R. G., Precursors for Atomic Layer Deposition of High-K Dielectrics. Future Fab International 2005, 18, 126-128.

6. Martensson, P.; Carlsson, J.-O., Atomic Layer Epitaxy of Copper on Tantalum. Chemical Vapor Deposition 1997, 3, (1), 45-50.

7. Per, M.; Jan-Otto, C., Atomic Layer Epitaxy of Copper. Journal of the Electrochemical Society 1998, 145, (8), 2926-2931.

8. $\quad$ Christopher, J.; Lanford, W. A.; Christopher, J. W.; Singh, J. P.; Pei, I. W.; Jay, J. S.; Toh-Ming, L., Inductively Coupled Hydrogen Plasma-Assisted Cu ALD on Metallic and Dielectric Surfaces. Journal of the Electrochemical Society 2005, 152, (2), C60-C64.

9. Raj, S.; Balu, P., Atomic Layer Deposition of Copper Seed Layers. Electrochemical and Solid-State Letters 2000, 3, (10), 479-480.

10. Huo, J.; Solanki, R.; McAndrew, J., Characteristics of copper films produced via atomic layer deposition. Journal of Materials Research 2002, 17, 2394-2398.

11. Utriainen, M.; Kröger-Laukkanen, M.; Johansson, L.-S.; Niinist, L., Studies of metallic thin film growth in an atomic layer epitaxy reactor using $\mathrm{M}(\mathrm{acac}) 2(\mathrm{M}=\mathrm{Ni}, \mathrm{Cu}, \mathrm{Pt})$ precursors. Applied Surface Science 2000, 157, (3), 151-158.

12. Antti, N.; Antti, R.; Timo, S.; Kai, A.; Mikko, R.; Markku, L., Radical-Enhanced Atomic Layer Deposition of Metallic Copper Thin Films. Journal of the Electrochemical Society 2005, 152, (1), G25-G28.

13. Li, Z.; Rahtu, A.; Gordon, R. G., Atomic Layer Deposition of Ultrathin Copper Metal Films from a Liquid Copper(I) Amidinate Precursor. Journal of Electrochemical Society 2006, 153, C787-C794.

14. Benouattas, N.; Mosser, A.; Raiser, D.; Faerber, J.; Bouabellou, A., Behaviour of copper atoms in annealed $\mathrm{Cu} / \mathrm{SiOx} / \mathrm{Si}$ systems. Applied Surface Science 2000, 153, (2-3), 79-84.

15. McBrayer, J. D.; Swanson, R. M.; Sigmon, T. W., Diffusion of Metals in Silicon Dioxide. Journal of the Electrochemical Society 1986, 133, (6), 1242-1246.

16. Li, Z.; Barry, S. T.; Gordon, R. G., Synthesis and Characterization of $\mathrm{Cu}(\mathrm{I})$ Amidinates as Precursors for Atomic Layer Deposition (ALD) of Copper Metal. Inorganic Chemistry 2005, 44, 1728-1735.

17. Higashi, G. S.; Chabal, Y. J., Silicon surface chemical composition and morphology, Chapter in Handbook of Silicon Wafer Cleaning Technology: Science, Technology, and Applications Werner Kern ed, Noyes Pub., 1993.

18. Weldon, M. K.; Marsico, V. E.; Chabal, Y. J.; Hamann, D. R.; Christman, S. B.; E. E. Chaban, S. S., Infrared Spectroscopy as a Probe of Fundamental Processes in Microelectronics: Silicon Wafer Cleaning and Bonding, . Surface Science 1996, 368, 163.

19. Kwon, J.; Dai, M.; Langereis, E.; Halls, M. D.; Chabal, Y. J.; Gordon, R. G., In-situ Infrared Characterization during Atomic Layer Deposition of Lanthanum Oxide. Journal of Physical Chemistry C 2009, 113, (2), 654-660.

20. Conley, R. T., Infrared Spectroscopy. Allyn and Bacon, Inc. 1972.

21. Yang, C.-Y.; Jeng, J. S.; Chen, J. S., Grain growth, agglomeration and interfacial reaction of copper interconnects. Thin Solid Films 2002, 420-421, 398-402. 
22. Ching-Yu, Y.; Chen, J. S., Investigation of Copper Agglomeration at Elevated Temperatures. Journal of the Electrochemical Society 2003, 150, (12), G826-G830. 